\title{
Environmental determinants of fish abundance in the littoral zone of gravel pit lakes
}

\author{
S. Matern $(\mathbb{D} \cdot$ T. Klefoth $(\mathbb{D} \cdot$ C. Wolter $\mathbb{C} \cdot$ R. Arlinghaus $\mathbb{1}$
}

Received: 30 June 2020/Revised: 15 February 2021/Accepted: 3 March 2021/Published online: 5 April 2021

(C) The Author(s) 2021

\begin{abstract}
The type and extent of habitats along the shoreline specify the distribution of fish in the littoral zone of lakes, but effects are likely species and sizespecific and might be overwhelmed by lake-level environmental factors that drive fish abundance (e.g. trophic state). We applied a replicated transect-sampling design by electrofishing assessing fish abundance and distribution along the banks of 20 gravel pit lakes in Lower Saxony (Germany). Boosted regression trees were used to analyse the impact of different characteristic habitat types (e.g. vegetated, woody or
\end{abstract}

Handling editor: Eric R. Larson

Supplementary Information The online version contains supplementary material available at https://doi.org/10.1007/ s10750-021-04563-4.

S. Matern $(\bowtie) \cdot$ C. Wolter $\cdot$ R. Arlinghaus

Department of Biology and Ecology of Fishes, Leibniz Institute of Freshwater Ecology and Inland Fisheries, Müggelseedamm 310, 12587 Berlin, Germany

e-mail: matern@igb-berlin.de

S. Matern · R. Arlinghaus

Division for Integrative Fisheries Management, Albrecht

Daniel Thaer-Institute of Agriculture and Horticulture, Faculty of Life Science, Humbolt-Universität zu Berlin, Philippstrasse 13, Haus 7, 10155 Berlin, Germany

T. Klefoth

Ecology and Conservation, Faculty of Nature and Engineering, Hochschule Bremen, City University of Applied Sciences, 28199 Bremen, Germany open water zones), shoreline water depth and lakelevel environmental variables on species-specific fish abundances. In contrast to earlier studies, lake-level environment and transect-level habitat type similarly influenced the abundances of differently sized fish species in the littoral zone of gravel pit lakes. The abundance of almost all fish species increased with lake productivity and extent of structured littoral habitats, mostly following non-linear relationships. Our work suggests that investments into the quality of littoral habitat, and not merely the control of nutrient inputs or other lake-level environmental factors, can promote abundance of most gravel pit lake fish species, in particular those who depend on the littoral zone for at least part of their life-cycle.

Keywords Fish distribution - Littoral fish community $\cdot$ Habitat enhancement $\cdot$ Fisheries management $\cdot$ Boosted regression trees $\cdot$ Spatial autocorrelation

\section{Introduction}

Littoral zones and the associated ecotones connect terrestrial and aquatic habitats (Schindler \& Scheuerell, 2002) and provide key habitat for many taxa in rivers and lakes (Pusey \& Arthington, 2003; Winfield, 2004; Strayer \& Findlay, 2010). Accordingly, littoral 
zones provide manifold biological, chemical and physical functions, serving as spawning, feeding and refuge habitats for fishes and wildlife, enabling nutrient cycling, buffering waves and offering substrate for the colonization by plants (Radomski \& Goeman, 2001; Pusey \& Arthington, 2003; Winfield, 2004; Strayer \& Findlay, 2010; Vander Zanden et al., 2011). The high structural complexity and heterogeneity of littoral zones is known to promote biodiversity, production and food web complexity (Benson \& Magnuson, 1992; Sass et al., 2006; Carey et al., 2010; Ziegler et al., 2017; Cunha et al., 2019).

Most lake fish use the littoral zone on diel, seasonal or ontogenetic scales (Hofmann \& Fischer, 2001; Amundsen et al., 2003; Westrelin et al., 2018) for feeding, spawning, nursery or as refuge habitat (Hölker et al., 2002; Lewin et al., 2004; Winfield, 2004). Yet, comparative studies across lakes, and time series analysis from individual lakes, have shown that lake-level environmental characteristics, in particular trophic state, morphology or water clarity, have stronger structuring effects on most lake fish communities than the quality and quantity of the habitats present in the littoral zone (Persson et al., 1991; Jeppesen et al., 2000; Diekmann et al., 2005; Mehner et al., 2005; Lewin et al., 2014). However, the characteristics of littoral habitats have been found to co-determine the abundance of selected fish species in the littoral zone (Fischer \& Eckmann, 1997; Brosse et al., 1999; Helmus \& Sass, 2008; Lewin et al., 2014), because availability and quality of littoral habitats may fundamentally constrain certain life-history stages (Scheuerell \& Schindler, 2004; Ahrenstorff et al., 2009).

In cultural landscapes, artificially created lentic water bodies, in particular gravel pit lakes, have become common landscape elements (Soni et al., 2014; Blanchette \& Lund, 2016). These artificial water bodies are often characterized by steep slopes, sandy habitats and high water depth (Gee, 1978; Blanchette \& Lund, 2016; Nikolaus et al. 2020). Correspondingly, the littoral zone of gravel pit lakes appears functionally simplified relative to those of natural lakes (Emmrich et al., 2014). An increased relative importance of littoral zones has been reported to affect the abundance of selected fish species in lakes with limited littoral zones (Gasith, 1991; Hampton et al., 2011; Lewin et al., 2014). Hence, the relevance of littoral habitat features for driving the fish abundance in the limited littoral zone of gravel pit lakes might overrule the effect of environmental lake-level characteristics. However, this has not been quantified, yet.

Littoral habitat structures mainly encompass wood, coarse woody debris, reeds and submerged macrophytes, which are known to affect the abundances of fish species in the littoral zone of lakes (e.g. Okun \& Mehner, 2005; Sass et al., 2012; Lewin et al., 2014). For example, after controlling for lake-level impacts rudd (Scardinius erythrophthalmus (Linnaeus, 1758)), tench (Tinca tinca (Linnaeus, 1758)) and northern pike (Esox lucius Linnaeus, 1758) have been found to be more abundant in complex habitats formed by submerged and emerged macrophytes, while European eel (Anguilla anguilla (Linnaeus, 1758)), perch (Perca fluviatilis Linnaeus, 1758) and roach (Rutilus rutilus (Linnaeus, 1758)) have been preferentially found in woody habitats (Perrow et al., 1996; Lewin et al., 2004, 2014). Ecological processes such as preferences for spawning substrate and foraging habitat might explain these findings. At the same time, too dense structures can also limit foraging success (Savino \& Stein, 1982, 1989; Diehl, 1988) and, thus, non-linear relationships with a peak at intermediate levels can be expected for the relationship of the extent of specific habitat structures and the abundance of selected species in the littoral zone of lakes.

In particular small fish face a trade-off between foraging and shelter seeking to avoid predation, which is at the cornerstone of classical ecological theory explaining habitat choice as a function of a growthsurvival trade-off (Werner \& Hall, 1988; Ahrens et al., 2012). Risk-sensitive foraging is under strong natural selection, and fish have evolved a sensitive repertoire to balance shelter seeking with foraging (Ahrens et al., 2012). Highly structured habitat is usually safe as is very shallow water for small-bodied fish, and these habitats are thus preferred by larval and juvenile fishes (e.g. Brosse \& Lek, 2002; Okun \& Mehner, 2005). As fish grow, risk of predation by gape-limited predators decreases (Lorenzen, 2000; Gaeta et al., 2018), which might loosen the attachment of larger-bodied fish to

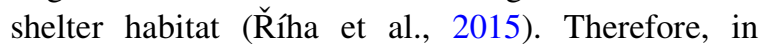
particular larval and juvenile fish of several species should benefit from functional littoral zones with shallow areas and structural complexity to cope with the growth-survival trade-off mentioned above by switching among foraging and refuge habitats (Brosse \& Lek, 2002). 
In lentic waters comparative studies of microhabitat use by fish have mainly focused on the effects of littoral substrates (e.g. sand or rocks) rather than littoral structures (e.g. submerged macrophytes or deadwood; Fischer \& Eckmann, 1997; Brosse et al., 1999; Brosse \& Lek, 2002; Šmejkal et al., 2014; Říha et al., 2015). Lewin et al. (2014) examined the relative importance of lake-level and shoreline-level environmental determinants of the abundance of fish species across German lakes. However, this study did not consider how the littoral zone might affect different size classes of fish. Abundances of small individuals should be more dependent on littoral habitat and shoreline characters (Poizat \& Pont, 1996; Grift et al., 2003; Pierce \& Tomcko, 2005), whereas the abundances of large individuals should be better predicted by lake-level environmental factors (Persson et al., 1991; Jeppesen et al., 2000; Mehner et al., 2005). To test this proposition, a species- and size-specific analysis was performed of fish distributions in the littoral zone (here the nearshore margin up to a maximum depth of $2 \mathrm{~m}$ ) of small gravel pit lakes, one of the most abundant and at the same time most understudied water body type in many cultural landscapes (Saulnier-Talbot \& Lavoie, 2018; Søndergaard et al., 2018).

We hypothesized that (I) the relative importance of lake-level vs. littoral-level environmental descriptors in driving fish abundance differs between species and size-classes, (II) increasing amounts of complex, littoral habitats and shallow areas positively affect abundances of small fish, and (III) the impact of different littoral structures on abundances of large fish is non-linear and species-specific, with thresholds expected in the relationship of littoral habitat and fish abundance.

\section{Methods}

Sampling location and data collection

We sampled the littoral fish abundance in 20 gravel pit lakes in the lowlands of Lower Saxony, North Western Germany, located in the Central Plains ecoregion (Fig. 1). For littoral electrofishing, we divided the entire shoreline of each lake into transects. The number of transects varied between 4 and 27 per lake. The individual transect length ranged from 30 to
$244 \mathrm{~m}$. All transects were sampled by boat electrofishing (FEG 8000 electrofishing device; $8 \mathrm{~kW}$; 150-300 V/300-600 V; EFKO Fischfanggeräte $\mathrm{GmbH}$; www.efko-gmbh.de) with one anodic hand net $(40 \mathrm{~cm}$ diameter and mesh size $6 \mathrm{~mm}$ ) once per year in autumn from 2016 to 2019. This configuration enabled an effective electric fishing field of about $5 \mathrm{~m}$ diameter. Accordingly, along each transect the activated anode was swiftly immersed every three to five meter and all immobilized fish were netted. In rare cases, the number of transects varied between sampling years for some lakes for logistical reasons, varying water levels and due to ongoing habitat management actions. In each transect, all fish were identified and total length was measured to the nearest $\mathrm{mm}$.

The transect-based sampling design was chosen to produce robust density estimates and to avoid zeroinflation of the data (e.g. Reid, 2011). Transect-based sampling further allowed the estimation of the relative composition of certain habitat types, e.g. the relative fraction of reed vs. woody habitat for a given transect. Electrofishing data were processed, and the catch per unit effort (CPUE) on transect-level was quantified for each year, lake and transect as individuals caught per $50 \mathrm{~m}$ electrofishing. Lake-level CPUE values were calculated as individuals caught per $50 \mathrm{~m}$ electrofishing per year and lake by summing up all catches and dividing them by the sum of all transect lengths. We then studied the effect of littoral structure on fish abundance (using transect-level CPUE in fish per $50 \mathrm{~m}$ as an abundance index), with transect-based CPUE values by size class and species nested as samples within lakes.

We confined our analysis of the relative impact of littoral structures, littoral water depth and lake-level environmental factors to six fish species, which regularly use and partly depend on the littoral zone in temperate European lakes: European eel, a relevant fisheries resource, the predators perch and pike, the benthivorous tench and the smaller-bodied "forage fish" roach and rudd. These species are common in German gravel pit lakes and naturally reproduce there, except for the stocked eel (Emmrich et al., 2014; Matern et al., 2019). To study the size-structured utilization of the littoral zone by fishes, all species except pike were separated into "small" and "large" size classes. For perch, roach, rudd and tench the threshold was set to $100 \mathrm{~mm}$ total length (TL). 


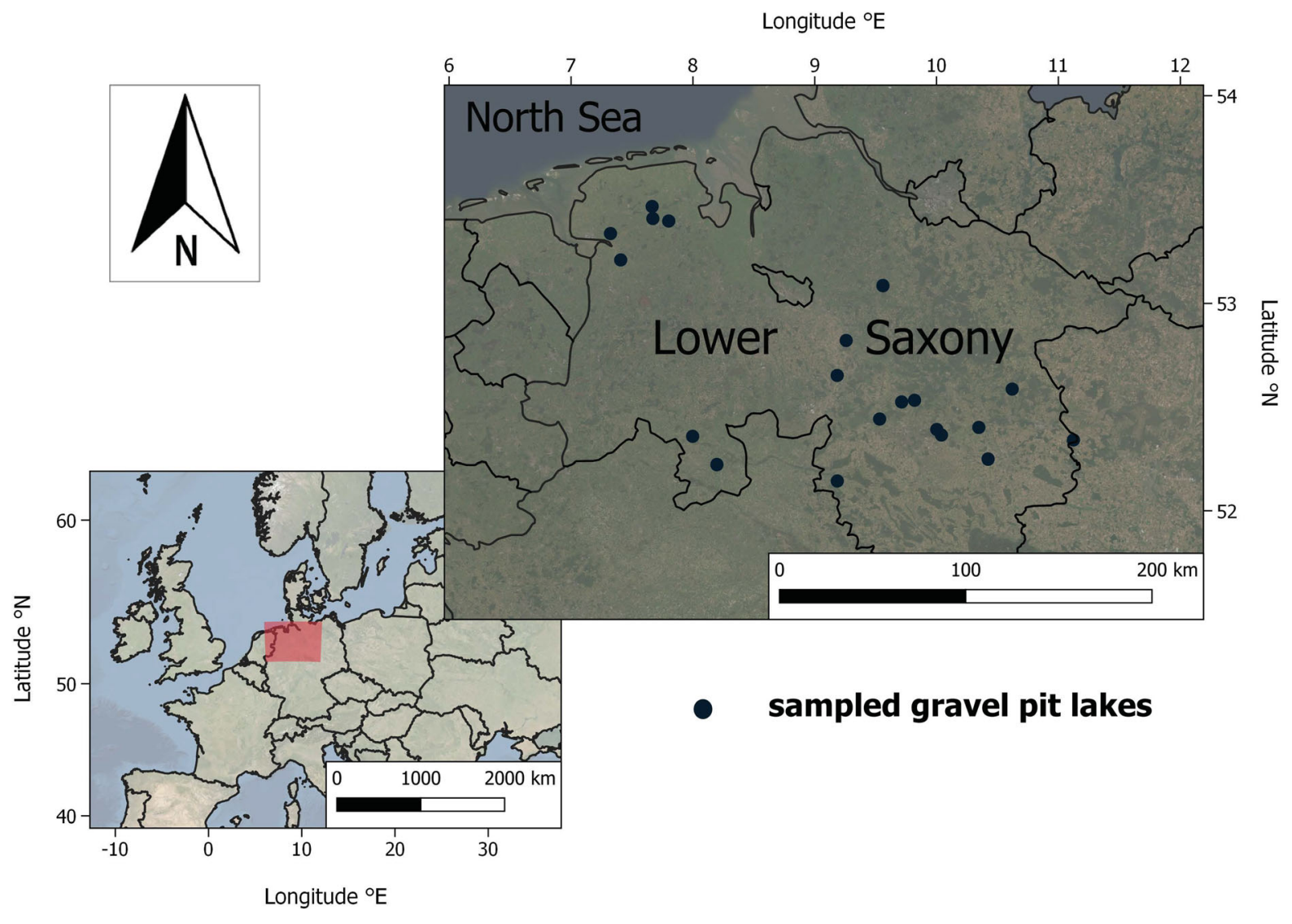

Fig. 1 Map of the gravel pit lakes in Lower Saxony, north-western Germany

Fish $\leq 100 \mathrm{~mm}$ TL are particularly vulnerable to predators (Gaeta et al., 2018) and should especially use structured habitats in the littoral zone. For the larger-bodied eel, the threshold was set at $300 \mathrm{~mm}$ TL. Pike was the only species analysed in three size classes: small ( $\leq 200 \mathrm{~mm}$ TL), medium ( $>200$ and $\leq 400 \mathrm{~mm} \mathrm{TL}$ ), and large (>400 $\mathrm{mm} \mathrm{TL})$ to account for size-related habitat choice as a consequence of decreasing risk of cannibalism with increasing length (Nilsson, 2006) and size-dependent reliance on submerged macrophytes previously reported in the literature (Casselman, 1996; Casselman \& Lewis, 1996).

Environmental lake-level variables

Lake area and shoreline length of the gravel pit lakes were calculated using QGIS (QGIS Development Team, 2019). The shoreline development factor (SDF) was calculated after Hutchinson (1957) as an index of shoreline complexity and extent. Mean and maximum lake depth and the percentage of shallow lake areas (less than $3 \mathrm{~m}$ depth) were extracted from depth contour maps that were calculated by ordinary kriging in R following Monk and Arlinghaus (2017). Conductivity and Secchi depth were measured at each sampling event above the deepest point of the lake. Furthermore, water samples of the epilimnion were taken to analyse the total phosphorus concentration (TP) and the chlorophyll a concentration ( $\mathrm{Chl}$ a) of the lakes to indicate trophic state. TP determination was conducted following the molybdenum blue method (Murphy \& Riley, 1962; ISO, 2004), and the Chl a concentration was determined using high performance liquid chromatography (Mantoura \& Llewellyn, 1983; Wright et al., 1991). To control for annual variation, Secchi depth, Chl a and TP values from two additional summer samplings (2017 and 2018) and one additional sampling in early spring (2017) were used to calculate a more robust mean for each lake. 
Transect variables and habitat structures along the shoreline

The extent of different shoreline structures and average transect depth were visually determined for each transect at every sampling event. We differentiated the extent (in percentage of transect length) of reeds, wood, deadwood, submerged macrophytes and the absence of structure, termed "open littoral". Reed habitats were mainly created by common reed (Phragmites australis) and in minor fractions by cattail (Typha sp.) and rush (Juncus sp.). The category "wood" was mainly represented by branches of living trees (various species) that extended from above the surface into the water column. Deadwood and roots were assigned to the category "deadwood" as they create a wooden structure in the water column and on the lake bottom. The category "submerged macrophytes" was represented by various species. For simplicity, some rare floating-leaved macrophytes, mainly water lilies (Nymphaea sp.), were also included in the category "submerged macrophytes". The fifth category "open littoral" represented littoral areas without any structures and open, mostly soft bottom or sandy substrates such as sandy beaches or unstructured angling sites. The average fished depth in each transect was estimated and noted as "littoral depth". Transects with a littoral depth of more than $2 \mathrm{~m}$ were removed from the analysis due to a reduced catchability of the electrofishing device (Zalewski \& Cowx, 1990). The variable littoral depth contained three levels: very shallow (VS; $<0.5 \mathrm{~m}$ ); shallow (S; $0.5-1.0 \mathrm{~m}$ ) and deep (D; 1.0-2.0 m).

\section{Data analysis}

We first conducted a principal component analysis (PCA) of the z-transformed lake-level variables mean lake depth, maximum lake depth, share of shallow lake area (0-3 m depth), TP, Chl a, Secchi depth, SDF and conductivity to reduce the dimensionality of the environmental data (Table S1 and Fig. S1 in Supplementary Information). The broken stick method was chosen as stopping rule in the PCA (Jackson, 1993). Only one relevant PC axis was retained, which displayed information about the lake's productivity. SDF and conductivity loaded on separate axes (Table S1 and Fig. S1 in Supplementary Information). PC scores from PC 1 were extracted and used for further analysis (Table 1). Two gravel pit lakes showed "unusual" productivities (one very high, the other very low), however, both lakes were kept for further analysis to cover a larger productivity gradient.

To model the influence of environmental predictors (lake-level and transect-level) on the abundances of the different size classes of the six fish species, we used boosted regression trees (BRTs), similar to Lewin et al. (2014). BRTs are a machine-learning technique that produces several simple models (trees) and combines (boosts) them to produce a model with an improved predictive performance (Elith et al., 2008; Buston \& Elith, 2011). BRTs are superior to other statistical methods (e.g. generalized mixed models and generalized additive models) in identifying the relative importance of different predictor variables when relationships are non-linear (Elith et al., 2006; Leathwick et al., 2006). Importantly, they are able to detect non-linear effects of the predictor variables on the dependent variable (Elith et al., 2008). BRTs were modelled separately by species and size class. We also used linear mixed effects models and found qualitatively similar results, and for the sake of space and comparability with Lewin et al. (2014) opted to only present the BRT results here.

Lake-level predictor variables included PC scores representing productivity and raw values of SDF and conductivity. SDF was used in the BRTs as it represents shoreline quantity. Conductivity was integrated in the analysis as it corrects for electrofishing gear effects, i.e. lower efficiency at low conductivity, and species-specific reactivity to electrofishing at different conductivity. Transect variables describing the littoral habitat comprised the extent (in percentage of each transect) of different shoreline structures as well as average transect depth (as categorical variable with three levels). The BRTs calculated a species- and size-class specific relative importance for each variable for fish abundance. These relative importance values were scaled so that all variables summed to 100 (Elith et al., 2008) and can be compared between all lake-level and all transect-level variables to reveal the overall importance of lake vs. transect effects for the abundance of each species and size-class.

The bag fraction determines the proportion of the dataset that is used to build a single tree. It should be set between 0.5 and 0.75 to receive robust results (Elith et al., 2008). In our analysis, the bag fraction for all BRTs was set at 0.75 to ensure highest accuracy 


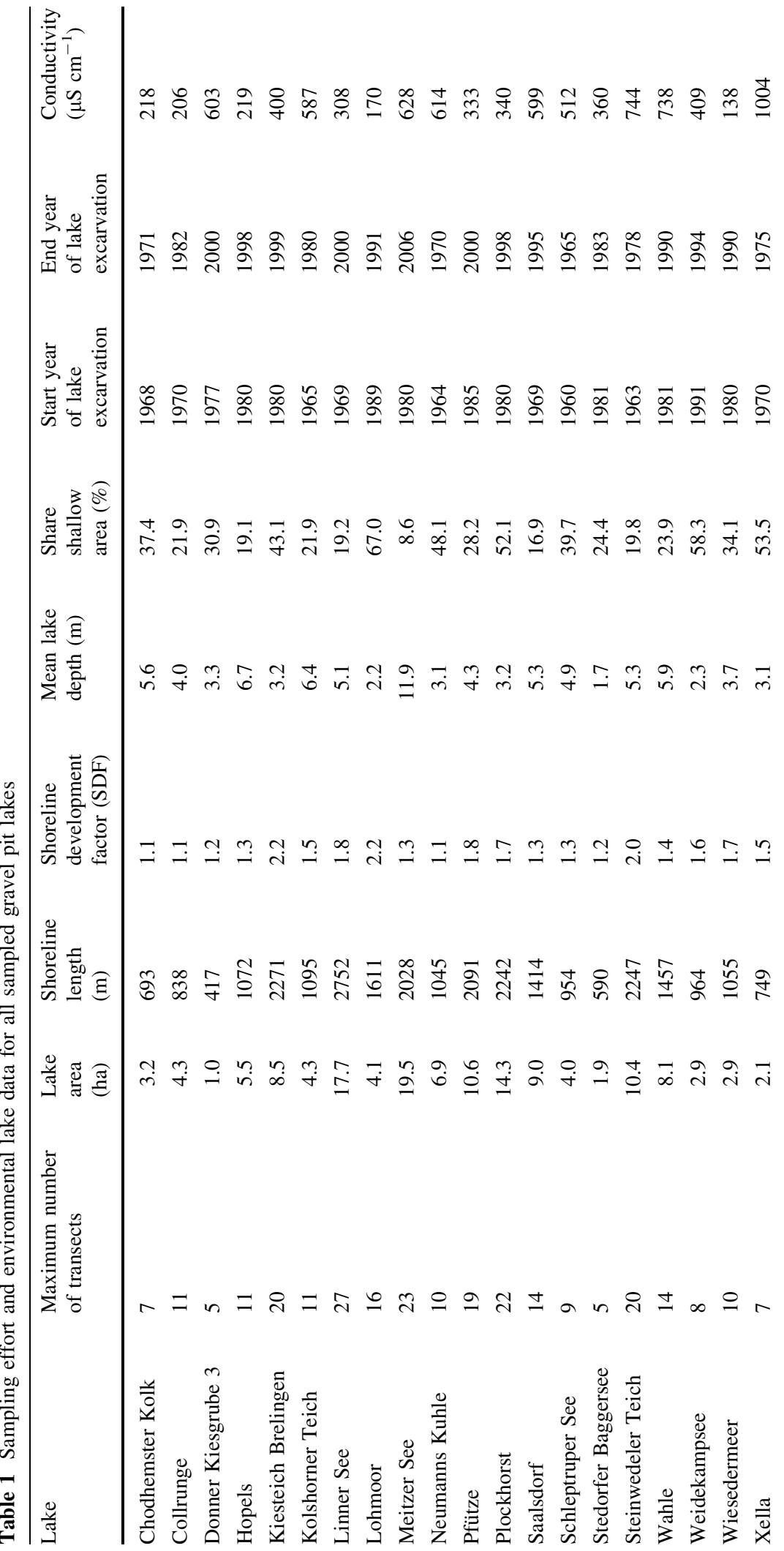




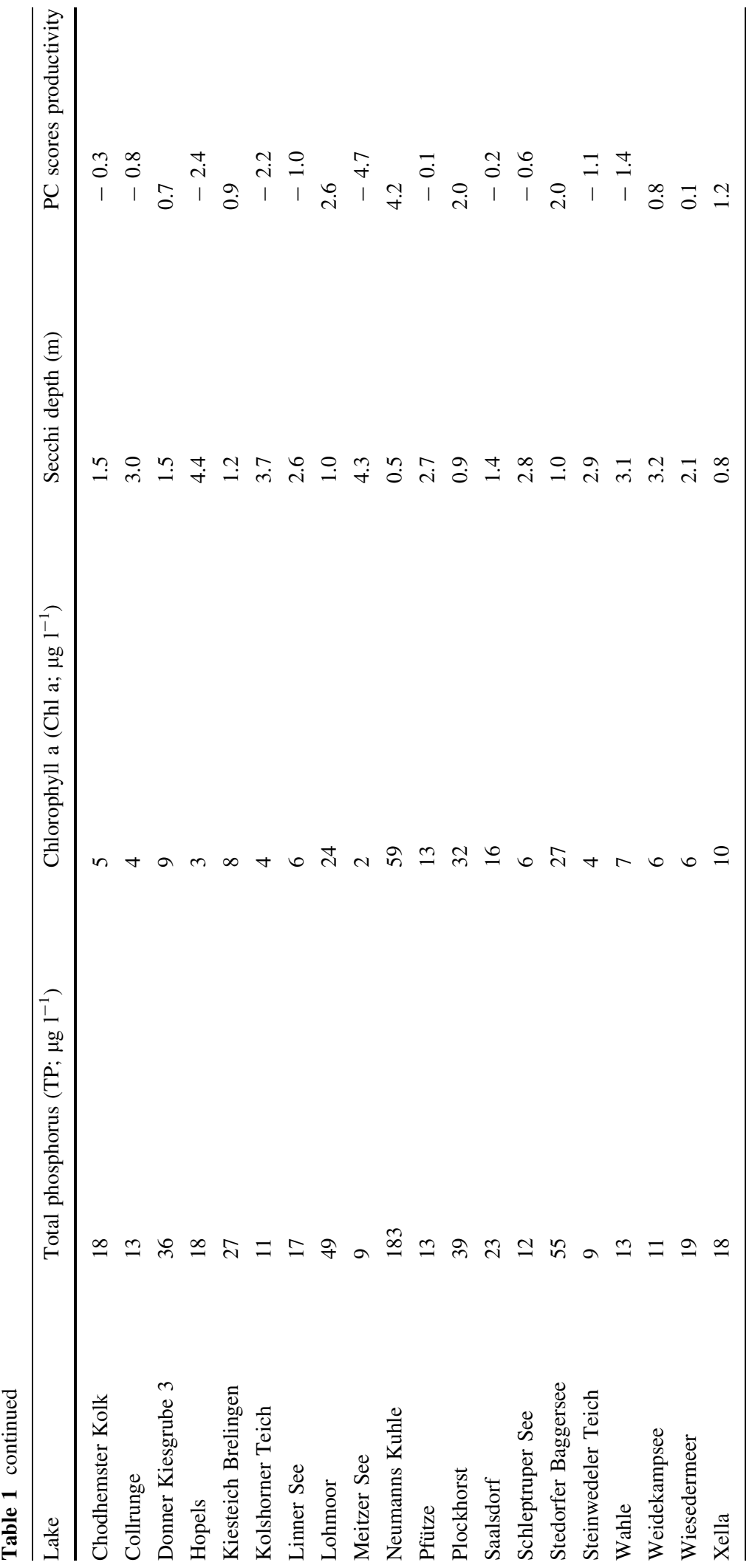


even for datasets with a low number of observations (e.g. large pike). The tree complexity was set to 5 to account for potential interaction effects in all BRT models. The learning rate was adjusted by species and size class to ensure at least 1000 trees per BRT model as recommended by Elith et al. (2008). The BRT output was displayed by using partial dependence plot to show the effect size of a variable on the response after accounting for the average effect of all other variables (Elith et al., 2008).

Fish abundances in neighbouring transects within a lake might be spatially autocorrelated violating assumptions of independence of data within lakes. Therefore, the spatial autocorrelation index Moran's I was separately estimated by fish species, lake and sampling event. Due to multiple comparisons, $P$ values were Šidák-corrected (Šidák, 1967). We found no evidence for spatial autocorrelation with just three detected events out of a total of 338 analyses (Table S2 in Supplementary Information) and thus rejected the assumption of autocorrelation. Each lake-year was assumed an independent sample as we were not interested in specific lake-level effects, similar to Lewin et al. (2014).

All statistical analyses were performed in $\mathrm{R}$ version 3.6.1 (R Core Team, 2019). The PCR was conducted using the package vegan (Oksanen et al., 2019), Moran's I was calculated using the package ape (Paradis \& Schliep, 2018), and the BRTs were modelled using the packages gbm (Greenwell et al., 2019) and dismo (Hijmans et al., 2017). BRT bootstrapping and visualization of the BRT results was conducted using modified commands of the ggBRT package (Jouffray et al., 2019).

\section{Results}

Lake environment and descriptive information on sampling outcomes

The gravel pit lakes were on average 7.1 ha in size with the smallest lake being 1 ha and the largest lake being 19.5 ha (Table 1). The SDF varied between 1.1 and 2.2 with an average of 1.5. Mean lake depth ranged between 1.7 and $11.9 \mathrm{~m}$ with an average of $4.4 \mathrm{~m}$, and the shallow areas comprised between 8.6 and $67 \%$ of the total lake area. The TP concentration ranged between 9 and $183 \mu \mathrm{g} \mathrm{l}^{-1}$ (average $30 \mu \mathrm{g} \mathrm{l}^{-1}$ ), and the Chl a concentration ranged between 2 and $59 \mu \mathrm{g} \mathrm{l}^{-1}$ (average of $13 \mu \mathrm{g}^{-1}$ ). The Secchi depth varied between 0.5 and $4.4 \mathrm{~m}$ (average $2.2 \mathrm{~m}$ ) and the conductivity between 138 and $1004 \mu \mathrm{S} \mathrm{cm}^{-1}$ (average $457 \mu \mathrm{S} \mathrm{cm}^{-1}$ ).

Open littoral was the dominant shoreline structure with a share of $35.1 \%$ over all lakes and sampling events (Table 2). Reeds and wood were also common in the littoral zone with relative frequencies of $22.9 \%$ and $24.2 \%$, respectively. Submerged macrophytes were only detected on $13.2 \%$ of the fished shoreline length, and deadwood represented the scarcest structure covering only $4.5 \%$ of the shorelines.

In total 65,261 individuals of 25 fish species were caught during 80 electrofishing surveys. The catch of all six fish species of interest summed up to a total of 53,853 fishes (Table 3). Small rudd ( $<100 \mathrm{~mm}$ TL) was the most abundant species and size class with 25,293 individuals, while large pike ( $>400 \mathrm{~mm}$ TL) were least abundant with 130 individuals, respectively. In eight gravel pit lakes, all six fish species were caught, while in three lakes only one or two of these species occurred (Table 4). Tench were caught in most of the lakes (90\%), followed by perch (85\%) and eel $(80 \%)$. Pike and roach were each caught in 15 gravel pit lakes $(75 \%)$, while rudd occurred least frequently (70\%). Accordingly, the number of lake samples used in the models varied by species and size class with a minimum sample size (lake sampling events) of 31 for large roach and a maximum of 64 for small perch (Table 3).

Highest median CPUE values (number of fish per $50 \mathrm{~m}$ ) were revealed for small perch with 4.8 (range 0.1-36.1) on lake level and 2.6 (range 0-123.8) on transect level (Table 3). The highest single species CPUE values were recorded for small rudd (lake level CPUE: 317.1; transect level CPUE: 779.1). Large pike were least abundant in the electrofishing catches with a median CPUE of 0.01 (range 0.01-0.56) on lake level and 0 (range $0-1.9$ ) on transect level. In general, the species CPUEs for larger size classes were lower than for smaller size classes, except for stocked eel.

Importance of lake-level vs. transect-level variables

Aggregated lake- and transect- habitat variables both showed similar relative importance for most species 


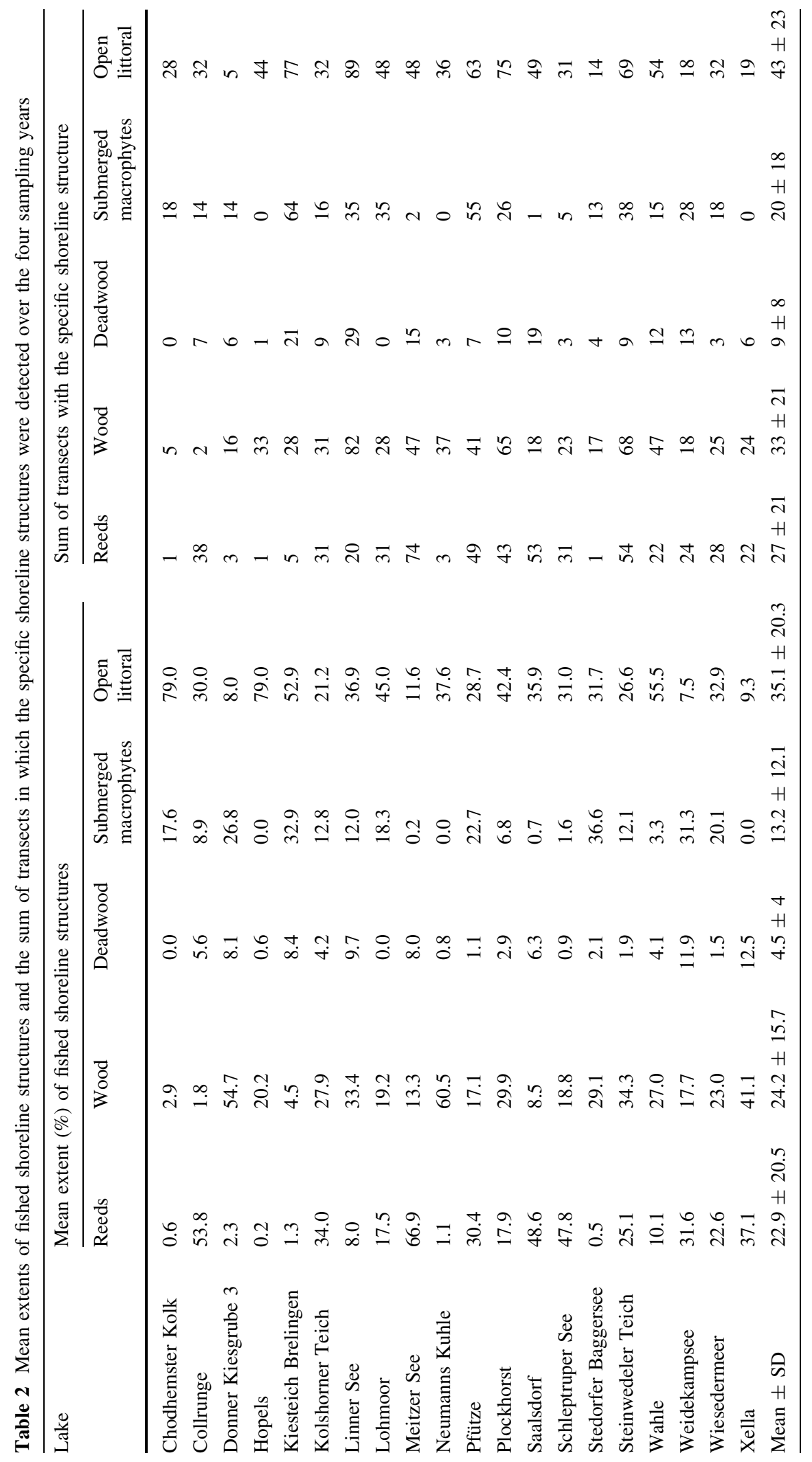




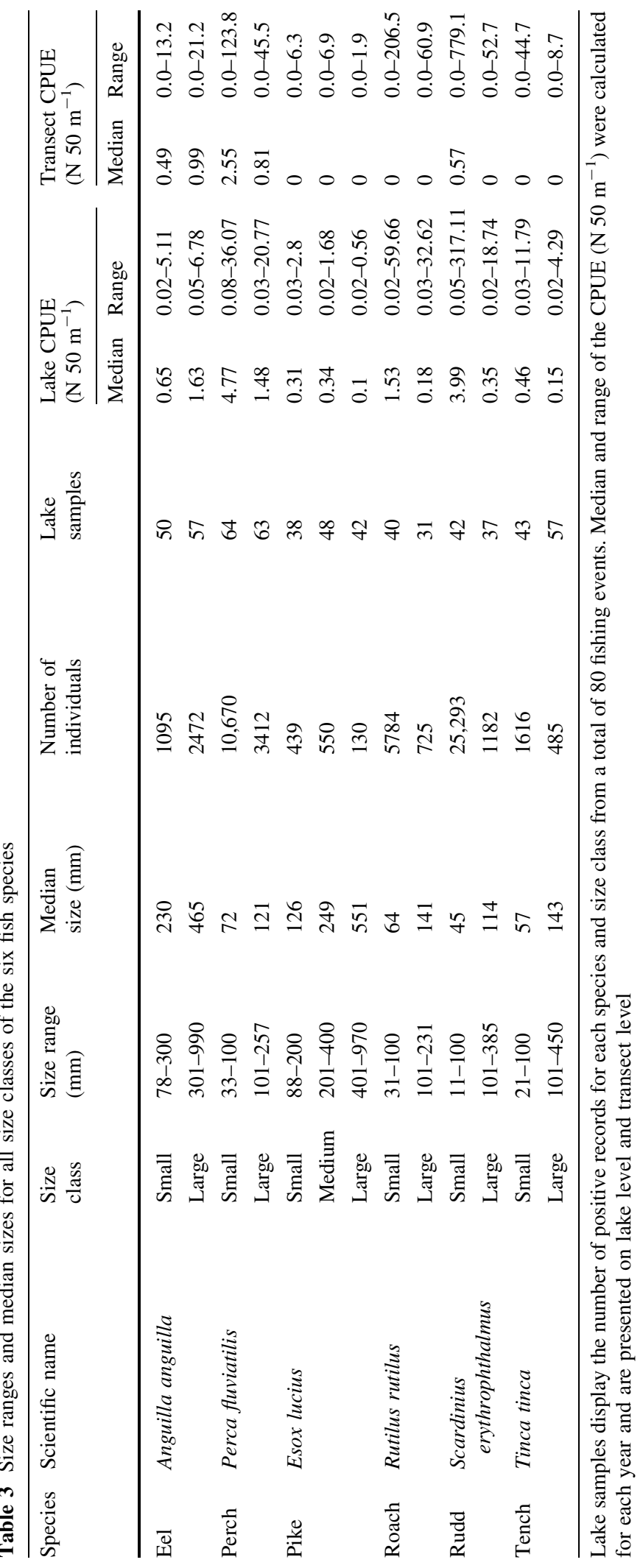


Table 4 Information on caught fish species ( $\mathrm{Y}=$ caught; $\mathrm{N}=$ not caught) for all sampled gravel pit lakes

\begin{tabular}{|c|c|c|c|c|c|c|}
\hline Lake & Eel & Perch & Pike & Roach & Rudd & Tench \\
\hline Chodhemster Kolk & $\mathrm{Y}$ & $\mathrm{Y}$ & $\mathrm{Y}$ & $\mathrm{Y}$ & $\mathrm{N}$ & $\mathrm{Y}$ \\
\hline Collrunge & $\mathrm{Y}$ & $\mathrm{Y}$ & $\mathrm{Y}$ & $\mathrm{Y}$ & $\mathrm{N}$ & $\mathrm{Y}$ \\
\hline Donner Kiesgrube 3 & $\mathrm{Y}$ & $\mathrm{Y}$ & $\mathrm{Y}$ & $\mathrm{Y}$ & $\mathrm{N}$ & $\mathrm{Y}$ \\
\hline Hopels & $\mathrm{Y}$ & $\mathrm{N}$ & $\mathrm{N}$ & $\mathrm{Y}$ & $\mathrm{N}$ & $\mathrm{N}$ \\
\hline Kiesteich Brelingen & $\mathrm{Y}$ & $\mathrm{Y}$ & $\mathrm{N}$ & $\mathrm{Y}$ & $\mathrm{Y}$ & $\mathrm{Y}$ \\
\hline Kolshorner Teich & $\mathrm{Y}$ & $\mathrm{Y}$ & $\mathrm{Y}$ & $\mathrm{Y}$ & $\mathrm{Y}$ & $\mathrm{Y}$ \\
\hline Linner See & $\mathrm{Y}$ & $\mathrm{Y}$ & $\mathrm{Y}$ & $\mathrm{Y}$ & $\mathrm{Y}$ & $\mathrm{Y}$ \\
\hline Lohmoor & $\mathrm{N}$ & $\mathrm{N}$ & $\mathrm{N}$ & $\mathrm{N}$ & $\mathrm{Y}$ & $\mathrm{N}$ \\
\hline Meitzer See & $\mathrm{N}$ & $\mathrm{Y}$ & $\mathrm{Y}$ & $\mathrm{Y}$ & $\mathrm{Y}$ & $\mathrm{Y}$ \\
\hline Neumanns Kuhle & $\mathrm{Y}$ & $\mathrm{Y}$ & $\mathrm{Y}$ & $\mathrm{Y}$ & $\mathrm{Y}$ & $\mathrm{Y}$ \\
\hline Pfütze & $\mathrm{N}$ & $\mathrm{Y}$ & $\mathrm{Y}$ & $\mathrm{N}$ & $\mathrm{N}$ & $\mathrm{Y}$ \\
\hline Plockhorst & $\mathrm{Y}$ & $\mathrm{Y}$ & $\mathrm{Y}$ & $\mathrm{Y}$ & $\mathrm{N}$ & $\mathrm{Y}$ \\
\hline Saalsdorf & $\mathrm{Y}$ & $\mathrm{Y}$ & $\mathrm{Y}$ & $\mathrm{Y}$ & $\mathrm{Y}$ & $\mathrm{Y}$ \\
\hline Schleptruper See & $\mathrm{Y}$ & $\mathrm{Y}$ & $\mathrm{Y}$ & $\mathrm{N}$ & $\mathrm{Y}$ & $\mathrm{Y}$ \\
\hline Stedorfer Baggersee & $\mathrm{Y}$ & $\mathrm{Y}$ & $\mathrm{Y}$ & $\mathrm{Y}$ & $\mathrm{Y}$ & $\mathrm{Y}$ \\
\hline Steinwedeler Teich & $\mathrm{Y}$ & $\mathrm{Y}$ & $\mathrm{Y}$ & $\mathrm{Y}$ & $\mathrm{Y}$ & $\mathrm{Y}$ \\
\hline Wahle & $\mathrm{Y}$ & $\mathrm{Y}$ & $\mathrm{N}$ & $\mathrm{N}$ & $\mathrm{Y}$ & $\mathrm{Y}$ \\
\hline Weidekampsee & $\mathrm{Y}$ & $\mathrm{Y}$ & $\mathrm{Y}$ & $\mathrm{Y}$ & $\mathrm{Y}$ & $\mathrm{Y}$ \\
\hline Wiesedermeer & $\mathrm{Y}$ & $\mathrm{Y}$ & $\mathrm{Y}$ & $\mathrm{Y}$ & Y & $\mathrm{Y}$ \\
\hline Xella & $\mathrm{N}$ & $\mathrm{N}$ & $\mathrm{N}$ & $\mathrm{N}$ & $\mathrm{Y}$ & $\mathrm{Y}$ \\
\hline$\sum$ & 16 & 17 & 15 & 15 & 14 & 18 \\
\hline Frequency of occurrence $(\%)$ & 0.8 & 0.85 & 0.75 & 0.75 & 0.7 & 0.9 \\
\hline
\end{tabular}

Table 5 Summed relative importance (\%) for all lake-level variables and all transect-level variables for all species and size classes; higher values in bold

\begin{tabular}{lllll}
\hline Species & Scientific name & size class & $\begin{array}{l}\text { Summed relative importance } \\
\text { of lake-level variables }(\%)\end{array}$ & $\begin{array}{l}\text { Summed relative importance } \\
\text { of transect-level variables }(\%)\end{array}$ \\
\hline Perch & Perca fluviatilis & Small & 48.0 & $\mathbf{5 2 . 0}$ \\
& & Large & 48.7 & $\mathbf{5 1 . 3}$ \\
Roach & Rutilus rutilus & Small & 46.7 & $\mathbf{5 3 . 3}$ \\
& & Large & $\mathbf{8 1 . 6}$ & 18.4 \\
Rudd & Scardinius erythrophthalmus & Small & 47.9 & $\mathbf{5 2 . 1}$ \\
& & Large & $\mathbf{5 5 . 5}$ & 44.5 \\
Tench & Tinca tinca & Small & $\mathbf{5 5 . 6}$ & 44.4 \\
& & Large & 49.0 & $\mathbf{5 1 . 0}$ \\
Eel & Anguilla anguilla & Small & $\mathbf{7 0 . 4}$ & 29.6 \\
& & Large & $\mathbf{6 1 . 8}$ & 38.2 \\
Pike & Esox lucius & Small & $\mathbf{5 3 . 2}$ & 46.8 \\
& & Medium & $\mathbf{5 0 . 2}$ & 49.8 \\
& & Large & 42.7 & $\mathbf{5 7 . 3}$
\end{tabular}

and size classes (Table 5), with few exceptions: The relative importance of lake- and transect-variables was $46.7 \%$ and $53.3 \%$, respectively, for small roach, while for large roach the lake-variables $(81.6 \%)$ were much more influential for the littoral abundance than transect-variables (18.4\%). This pattern was strongly 


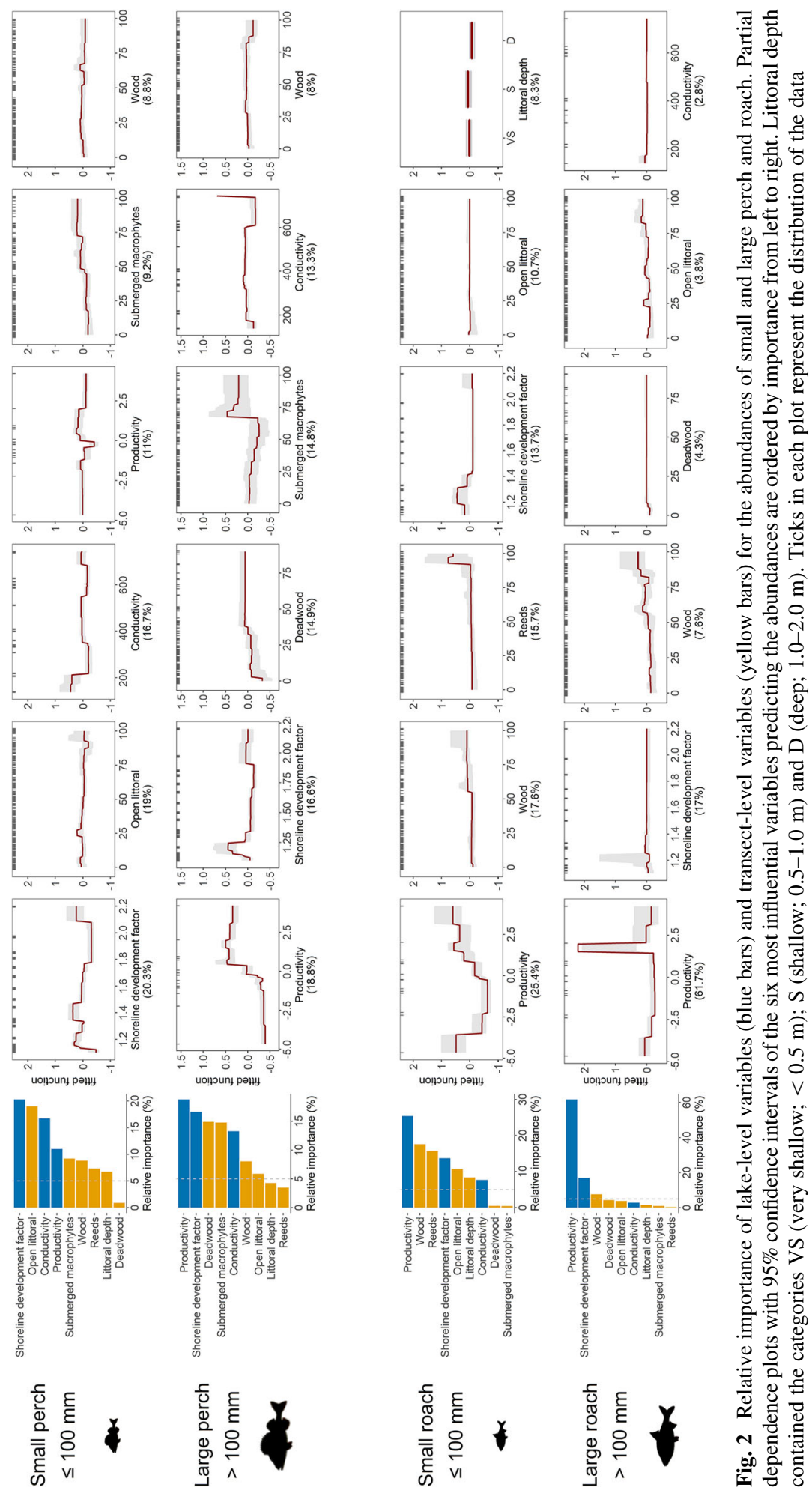




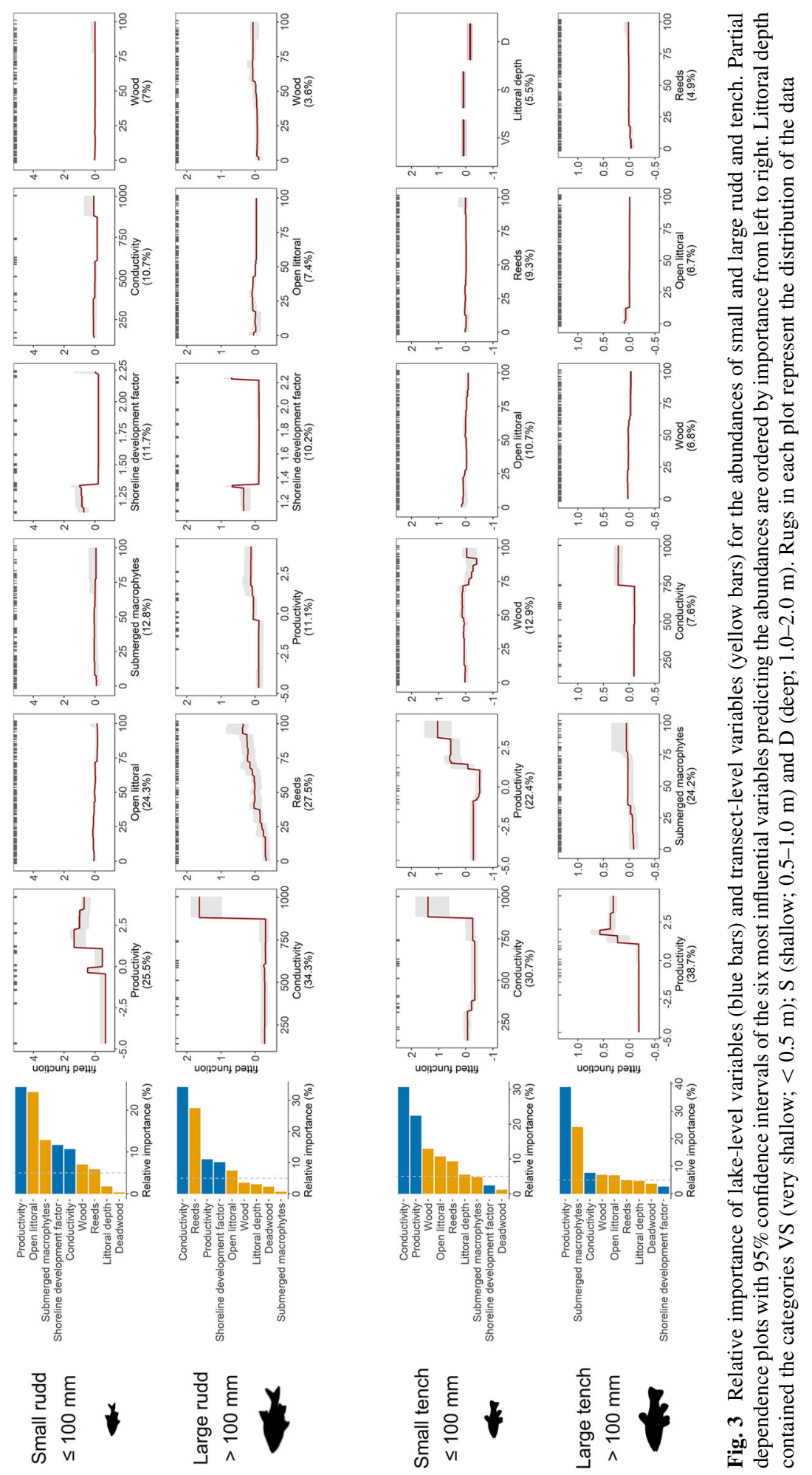




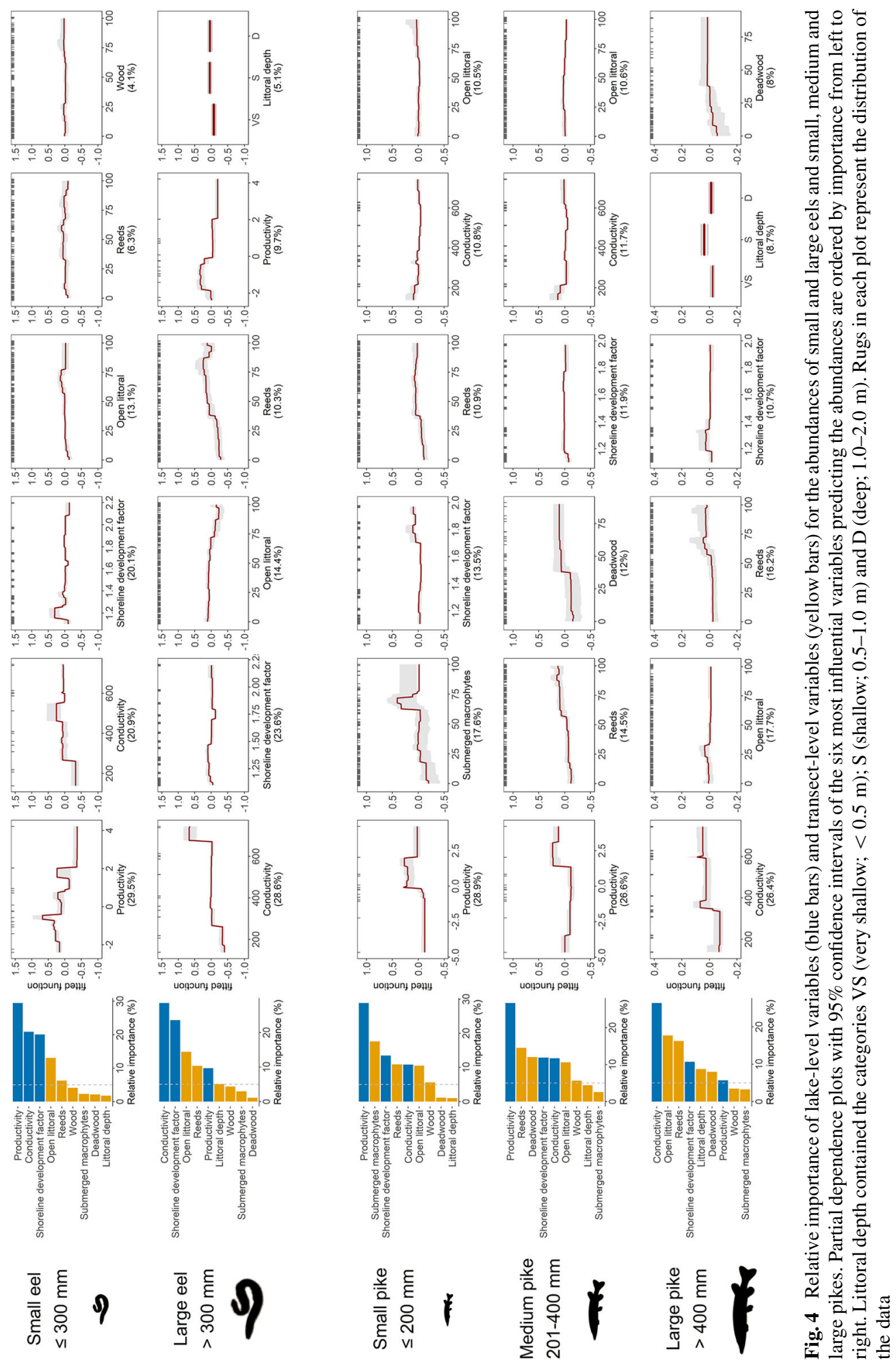


driven by the high relevance of lake productivity (61.7\%; Fig. 2) for large roach. For stocked eel, the relative importance of lake-variables also exceeded those of transect-variables with $70.4 \%$ for small eels and $61.8 \%$ for large eels. For pike the relative importance of the transect-variables compared to lake-level variables increased with size classes (small: 46.8\%; medium; $49.8 \%$ and large: $57.3 \%$ ), and the importance of lake-level variables decreased accordingly (small: 53.2\%; medium: 50.2\% and large: $42.7 \%$ ).

\section{Lake-level effects}

In each of the species and size classes, one of the lake-level variables had the highest relative importance in affecting fish abundance (Figs. 2, 3 and 4). In all cases, except for small perch, productivity or conductivity most strongly explained the observed abundances. The abundance of small perch was best explained by the SDF, a variable measured on lakelevel, but describing the quantity of littoral habitat (Fig. 2). With the exception of large rudd, productivity was of high relative importance for the three cyprinid species roach (small: $25.4 \%$; large: $61.7 \%$ ), rudd (small: $25.5 \%$ ) and tench (small: $22.4 \%$; large: $38.7 \%$ ). In all cases, abundances of these three species increased at higher productivity levels. Productivity was also of highest relative importance for large perch (18.8\%), small pike (28.9\%) and medium sized pike $(26.6 \%)$. For large perch and mediumsized pike increasing productivity led to increases in abundance, while abundances of small pike and also small perch peaked at an intermediate level of productivity.

Conductivity positively affected CPUE and appeared of high relative importance for abundances of eel (small: 20.9\%; large: 28.6\%), small tench $(30.7 \%)$, large rudd $(34.3 \%)$, and large pike $(26.4 \%)$. A relatively high importance of conductivity was also detected for perch (small: 16.7\%; large: 13.3\%), but without a clear positive or negative effect on the fish catches.

The SDF was of high relative importance for the abundance of all size classes of perch (small: 20.3\%; large: $16.6 \%$ ), roach (small: $13.7 \%$; large: $17 \%$ ), eel (small: $20.1 \%$; large: $23.6 \%$ ), and pike (small: $13.5 \%$; medium 11.9\%; large: $10.7 \%$ ); however, no clear direction of the effect was detected (Figs. 2, 3 and 4).
Importance of specific littoral habitats

Relative importance, effect size and direction of effects of the different habitat structures varied for fish species and size classes. At transect level open littoral best described the abundance of small perch (19\%), small rudd $(24.3 \%)$, eel of both size classes (small: $13.1 \%$, large: $14.4 \%)$ and large pike (17.7\%). Increasing shares of unstructured, open littoral correlated with decreasing abundances of all species, except small eel. Wood was the most important habitat variable for explaining the abundance of small tench (12.9\%), small and large roach $(17.6 \%$ and $7.6 \%)$. High shares of over $50 \%$ wood in the littoral zone were positively related to the abundance of small and large roach, while abundances of small tench decreased at over $70 \%$ wood within a transect. A high relative importance of deadwood was found for explaining the abundance of large perch $(14.9 \%)$ and medium sized pike $(12 \%)$. Shares of $40 \%$ deadwood on the shoreline had the largest effects, but the number of transects with high deadwood abundances was low (Figs. 2 and 4). Reeds were found an important habitat variable for the abundance of small roach $(15.7 \%)$, large eel $(10.3 \%)$, large rudd $(27.5 \%)$, as well as all size classes of pike (small: $10.9 \%$, medium: $14.5 \%$ and large: $16.2 \%$ ). Except for small roach, reeds influenced the fish abundances positively. Finally, submerged macrophytes were found highly important for the abundance of large perch $(14.8 \%)$ and small pike (17.6\%). Littoral depth had the highest relative importance for explaining the abundances of small roach $(8.3 \%)$ and large pike $(8.7 \%)$. In both cases highest abundances were detected in shallow water.

Non-linearities and threshold effects

There were several non-linear responses of fish abundance to habitat features and lake-level variables. In particular, non-linear relationships among a variable and fish abundance were detected for productivity impacts on tench of both size classes (Fig. 3). Abundances of large perch also increased with productivity in a non-linear pattern, with a threshold value that was smaller than the one for tench.

Non-linear pattern and threshold effects were also detected for habitat variables measured at transect level. For large perch and small pike, abundances peaked at an intermediate submerged macrophytes cover of approximately $70 \%$ and declined thereafter 
(Figs. 2 and 4). By contrast, deadwood was an important shoreline structure for medium sized pike and large perch reaching highest abundances at about $40 \%$ of deadwood, while even larger amounts did not further affect the abundances. For medium and large pike, abundances strongly increased in reed-dominated transects at a threshold of at least 50\% reed cover.

\section{Discussion}

General findings

We studied the influence of specific shoreline structures on littoral fish species by comparing the importance of littoral habitats to those of environmental lake-level variables on species-specific abundances. In support of $\mathrm{H} 1$, the importance of littoral habitats was found to be species- and size-specific, and in some cases (e.g. both size classes of perch), the transect variables better explained the abundances than the lake-level environmental variables. This finding shows that the littoral fish abundance was strongly influenced by the littoral environment in gravel pit lakes. We further hypothesized a positive effect of specific littoral structures especially on the abundances of small fishes (H2), which was confirmed only for small and medium sized pike. Furthermore, we found non-linear patterns with species- and size-class specific threshold effects for certain shoreline structures on fish abundance $(\mathrm{H} 3)$, in particular vegetation, woody structures and the extent of fully unstructured habitats. Littoral depth played only a minor role for fish abundances in gravel pit lakes, indicating that in our study lakes the habitat types were dominant factors affecting transect-level fish abundance.

Lake-level vs. transect-level impacts on fish abundance

Our results revealed a high importance of both, lake environment and shoreline habitats, for the local abundance of most species and size-classes. Lakelevel environmental variables, such as morphology and nutrient level, are known to be important drivers of lake fish communities and abundances (Persson et al., 1991; Jeppesen et al., 2000; de Leeuw et al., 2003; Mehner et al., 2005; Lewin et al., 2014).
However, in our work the combined effect of all littoral variables was of similar or sometimes even higher importance than that of the pooled lake environment for driving local fish abundance in gravel pit lakes. Littoral structures are known to be crucial for the lifecycle of certain lentic fish species (e.g. pike; Casselman \& Lewis, 1996; Nilsson et al., 2014) and hence changes in the shoreline habitat strongly affect fishes on species and community levels as well as abundance (Whitfield, 1986; Sass et al., 2006, 2012; Helmus \& Sass, 2008; Ziegler et al., 2017). Using a similar methodological approach to ours, Lewin et al. (2014) found substantially higher importance of lakelevel variables compared to the littoral characteristics in natural German lakes (compare Table S3). Our results are different, by revealing a higher relative importance of littoral variables compared to lake-level variables in gravel pit lakes. Compared to natural lakes, man-made gravel pit lakes are often characterized by steep slopes and higher littoral depth (Gee, 1978; Emmrich et al., 2014) and thus the distribution of submerged macrophytes and reeds is often more limited (Duarte \& Kalf, 1986). The amount of deadwood is also lower in gravel pit lakes than in natural lakes, due to their young age (Robichon, unpublished data). Because of these deficits in littoral structures, their relative increases may have a stronger impact in gravel pit lakes compared to natural lakes with natural shorelines studied by Lewin et al. (2014). Nevertheless, the littoral fish community structure does not differ between gravel pit lakes and natural lakes as found in previous work in the same study region (Emmrich et al., 2014).

\section{Lake-level environmental effects}

We found lake productivity as an important, but not outstanding factor influencing littoral fish abundances in small gravel pit lakes. The relevance of the lake's trophic state for fish abundance is well established in the fish ecological literature: productivity and carrying capacity for fish biomass are strongly related to nutrient levels (Hanson \& Leggett, 1982; Downing et al., 1990). Abundances of cyprinid species peak in eutrophic to polytrophic lakes, because these species benefit from increasing algal biomass and related zooplankton as food source (Persson et al., 1991; Jeppesen et al., 2000; de Leeuw et al., 2003; Mehner et al., 2005). Our study mostly included oligotrophic to 
mesotrophic lakes and this might have downplayed the relevance of trophic state as key lake environmental factor, relative to Lewin et al. (2014). Nevertheless and in line with literature, we also saw a strong relevance of our productivity index for abundances of cyprinids, particularly roach and tench, in the littoral zone. Abundances of pike and perch have previously found to peak at a meso- to slightly eutrophic state and decrease afterwards (Persson et al., 1991; Jeppesen et al., 2000; de Leeuw et al., 2003; Mehner et al., 2005; Lewin et al., 2014). Similarly, Haugen \& Vøllestad (2018) reported highest pike abundance at intermediate phosphorus concentrations of $15 \mu \mathrm{g}^{-1}$ in shallow lakes, likely because of the loss of macrophytes with increasing trophic state. We detected only small perch and small pike abundances to peak at intermediate productivity levels, while medium sized pike and large pike benefited from higher productivity levels, suggesting that the trophic states we observed were not limiting to the abundance of pike. Relatedly, Jeppesen et al. (2000) failed to find inverse relationships of productivity and abundance of pike in shallow lakes in Denmark, and Haugen \& Vøllestad (2018) reported no decline of pike abundance with nutrient levels in deep lakes, indicating that pike can tolerate a wide range of productivities and might even benefit from increasing trophic state through higher prey availability (Nilsson et al., 2009). Overall, our lakes did not consistently cover the full productivity gradient from oligotrophic to polytrophic states and, thus, we might not have covered the threshold of decreasing abundances with elevated trophic state.

We found SDF to be of major importance for perch abundances. The SDF broadly describes the availability of littoral habitats. The littoral zone displays an important habitat for fishes, especially in deep lakes, by providing food (Hampton et al., 2011) and shelter from predators (Beauchamp et al., 1994; Stoll et al., 2008). Perch, the dominating fish species in mesotrophic natural lakes (Persson et al., 1991; Mehner et al., 2005) and gravel pit lakes (Matern et al., 2019), highly rely on the littoral zone during their ontogeny (Amundsen et al., 2003). Furthermore, SDF is an important factor determining growth of perch as revealed for some of our study lakes (Höhne et al., 2020). Hence, our findings are in accordance with perch literature and show the SDF as good surrogate to explain not only growth (Höhne et al., 2020), but also abundance of perch.
Conductivity was identified as important lake-level variable especially for the catch of large pike, rudd and eel, but also of small tench. Generally, the catches of all species and size classes were positively related to conductivity. Conductivity is known to influence the size of the electric field created through the electrofishing device, with larger efficient field sizes at higher conductivity (Bohlin et al., 1989; Zalewski \& Cowx, 1990) and hence increased catches. However, at low conductivity catches of larger individuals were disproportionally lower and probably the abundances were also underestimated in low conductivity lakes.

\section{Effect of littoral structures at the transect level}

We found a strong positive effect of specific littoral structures on abundances of small and medium sized pike. The observed abundances of small pike peaked in highly, but not completely macrophyte-dominated transects, which is in agreement with previous studies (Grimm, 1989; Casselman \& Lewis, 1996). While low or entirely unvegetated habitats were avoided due to increased risk of cannibalism (Grimm \& Klinge, 1996; Skov et al., 2003; Skov \& Koed, 2004), too dense habitat structures might limit foraging success (Savino \& Stein, 1989; Eklöv, 1997), explaining the detected patterns. Abundances of medium sized pike increased in less complex reeds and deadwood, which corresponds with previously reported raising independence from vegetation cover with increasing body size in this species (Chapman \& Mackay, 1984; Rosell \& MacOscar, 2002; Kobler et al., 2008, 2009).

The expected highest abundances of large fish in medium-structured habitats were only observed for large perch. Perch are superior competitors to roach in medium structured littoral habitats (Persson \& Eklöv, 1995), however, highly complex and dense aquatic vegetation negatively influences foraging efficiency of percids (Savino \& Stein, 1982; Diehl, 1988; Gotceitas \& Colgan, 1989) and, thus, abundances (Brosse \& Lek, 2002). Our results suggest that similarly to pike, large perch benefit from intermediate macrophytes coverage.

Submerged macrophytes were also highly relevant for large tench and this pattern was rather linear. Tench select for densely vegetated habitats of floating and submerged macrophytes, as well as reeds (Perrow et al., 1996; Gallardo et al., 2006; Lewin et al., 2014). Hence, highest tench abundances can be expected in 
habitats with highest structural complexity, which is in agreement with our results.

A further positive linear effect was detected for littoral reed stands on large rudd abundances. Aquatic vegetation has always been stated as typical rudd habitats (Eklöv \& Hamrin, 1989), but Lewin et al. (2014) already revealed a higher relevance of reed habitats compared to submerged macrophytes for rudd abundance. Our results confirm this finding for rudd larger $100 \mathrm{~mm}$.

Open littoral was found to negatively affect the abundance of small rudd and large eels. Lewin et al. (2014) found similar eel abundances in structured and unstructured habitats, but did not investigate size effects. River studies on Anguilla species showed an increased importance of riparian cover for eels larger $300 \mathrm{~mm}$, while smaller individuals selected for diverse sediments as shelter habitat (Jellyman et al., 2002; Glova et al., 2010). Hence, the absence of littoral cover negatively affects the abundances of larger eels, while small eel abundances might be more influenced by the diversity of the sediment, a variable not measured here. Furthermore, our findings indicate a general dependence of small rudd and large eel on littoral habitat complexity, but not specifically on a distinct habitat type.

Importance of littoral water depth was generally low throughout all species and size classes compared to littoral structures. Generally, shallow water zones are often stated as habitat for fishes because they warm quicker and offer refuge from larger bodied predators (e. g. Paterson \& Whitfield, 2000), and Brosse et al. (1999) detected a higher species-specific importance of littoral depth. However, Brosse et al. (1999) conducted electrofishing from June to mid-September, while our sampling was conducted from end of August to mid-October. Hence, littoral depth might be particularly important for larval fishes, and the importance of littoral depth decreases with increasing fish size.

Special case of stocked eel

Pattern and variances in eel catches were best explained by lake-level rather than transect-level variables. Lewin et al. (2014) already detected a high importance of the lake-level variables "trophic index" and "mean lake depth" on eel abundances in shallow lakes. In shallow lakes eel abundances and growth rates are usually highest at high trophic levels
(Anwand, 1982; Lewin et al., 2014). In comparison to that, in deep lakes shoreline development factor and shoreline structure become more important for eel (Lewin et al., 2014). However, eel populations in unconnected gravel pit lakes completely rely on stocking through recreational-fisheries management (Emmrich et al., 2014; Matern et al., 2019), which can positively impact their abundances if the environment offers suitable conditions (Simon \& Dörner, 2014; Arlinghaus et al., 2015). Our analysis did not consider stocking effects on lake-level and, therefore, does neither allow for an accurate interpretation of the lake variable effects nor for a comparison of lake environment vs. littoral habitat effects as these results may be biased by individual stocking actions per lake. Nevertheless, the comparison of the different shoreline structures and their specific effects on the eel abundances remain valid.

Study limitations and future research needs

In our study, all data were collected by electrofishing, which is known for being size and species-selective and exhibiting lower efficiency in deep water and open habitats. However, it is still the most broadly applicable standard method for fish sampling in littoral habitats (Mueller et al., 2017). We analysed conductivity effects to account for lake-specific catchability. Nevertheless, the abundances of large fish in general and of all fish in the unstructured, open littoral habitats might have been underestimated. However, even if absolutely underestimated, at higher stock densities relatively more large fish get captured and also more fish in the less structured habitats should have been caught, such that the relative differences among habitats should broadly hold.

In our study, we exclusively used data from daytime electrofishing samplings in autumn (end of August until mid-October). Littoral habitat utilization of fishes differs between day and night (Copp, 2010; Říha et al., 2015) and between seasons (Kobler et al., 2008; Nakayama et al., 2018; Westrelin et al., 2018). Hence, fish samplings over all seasons and both times of the day might reveal other patterns than we presented here. Future research focusing on these aspects would complete the knowledge of the littoral zone to verify its importance for the fish abundance in gravel pit lakes. As a final limitation, we have to mention that we did not fully randomly select study 
lakes such that our inferences are confined to the environmental gradients characteristic of our study lakes. However, in the study region, similar to many other cases in central Europe, most gravel pit lakes are mesotrophic (Emmrich et al., 2014; Zhao et al., 2016; Søndergaard et al., 2018) and match the environmental characteristics of our study lakes. Therefore, our results remain transferable to most gravel pit lakes in Europe and might also hold for natural lakes of similar ecological conditions.

\section{Conclusions and implications}

Our results suggest that the availability and characteristics of littoral habitats are highly relevant and shape the abundance of littoral fish in gravel pit lakes, and in certain cases (e.g. perch of both size classes) their importance can even exceed those of environmental lake-level effects. We further demonstrated that fish-habitat associations are dependent on the species, size-class and the type of littoral habitat, often revealing non-linearities and threshold effects. Hence, we recommend that fisheries managers should not only rely on stocking and harvest regulations, but also consider habitat enhancement in the littoral zone of lakes as a suitable means to manage fish abundance in lakes (Sass et al., 2017). Generally, increasing amounts of littoral structure lead to increasing fish abundances for most species, with exceptions of small pike and large perch, which benefit from intermediate coverage of submerged macrophytes. We can conclude that diverse shoreline structures and the availability of various habitat types support a diverse fish community (e.g. Werner et al., 1977; Dustin \& Vondracek, 2017) and elevate fish abundance in gravel pit lakes. These results are likely to hold for natural water bodies with degraded shorelines as well.

Acknowledgements We would like to thank Kate Laskowski, Christopher Monk, Rob Ahrens, Johannes Radinger and Christian Lewin for their statistical support. We further thank the chemical department at IGB for the analyses of water samples, and Barbara Stein and Asja Vogt for analyses of chlorophyll a samples. We appreciate the help from IGB staff, especially Alex Türck, students and interns during fieldwork and we thank Angelsportverein Leer u. Umgebung e.V., Bezirksfischereiverband für Ostfriesland e.V., Angler-Verein Nienburg e.V., ASV Neustadt am Rübenberge e.V., Fischereiverein Hannover e.V., Niedersächsisch-Westfälische Anglervereinigung e.V., Stiftung Naturschutz im Landkreis
Rotenburg (Wümme), Henning Scherfeld, FV Peine-Ilsede u. Umgebung e.V., SFV Helmstedt u. Umgebung e.V., Verein der Sportfischer Verden (Aller) e. V., Verein für Fischerei und Gewässerschutz Schönewörde u. Umgebung e.V., Steffen Göckemeyer, and the Angler Association of Lower Saxony for participating in this study. We also want to thank the three anonymous reviewers for their helpful comments on the manuscript. This work was jointly supported by the German Federal Ministry of Education and Research (BMBF) and the German Federal Agency for Nature Conservation (BfN) with funds granted by the German Federal Ministry for the Environment, Nature Conservation and Nuclear Safety (BMU; Grant Number: 01LC1320A).

Author contributions SM: data generation, data analysis and interpretation, manuscript preparation; TK, CW and RA: conceptualization of the study, data interpretation, manuscript editing, funding.

Funding Open Access funding enabled and organized by Projekt DEAL.

Data availability The datasets generated during and/or analysed during the current study are available from the corresponding author on reasonable request.

Declarations Our fish sampling complied with fisheries law in Lower Saxony, Germany and included permissions for electrofishing.

Conflict of interest The authors have no conflict of interest.

Open Access This article is licensed under a Creative Commons Attribution 4.0 International License, which permits use, sharing, adaptation, distribution and reproduction in any medium or format, as long as you give appropriate credit to the original author(s) and the source, provide a link to the Creative Commons licence, and indicate if changes were made. The images or other third party material in this article are included in the article's Creative Commons licence, unless indicated otherwise in a credit line to the material. If material is not included in the article's Creative Commons licence and your intended use is not permitted by statutory regulation or exceeds the permitted use, you will need to obtain permission directly from the copyright holder. To view a copy of this licence, visit http://creativecommons.org/licenses/by/4.0/.

\section{References}

Ahrens, R. N. M., C. J. Walters, \& V. Christensen, 2012. Foraging arena theory. Fish and Fisheries 13: 41-59

Ahrenstorff, T. D., G. G. Sass, \& M. R. Helmus, 2009. The influence of littoral zone coarse woody habitat on home range size, spatial distribution, and feeding ecology of largemouth bass (Micropterus salmoides). Hydrobiologia 623: 223-233 
Amundsen, P.-A., T. Bøhn, O. A. Popova, F. J. Staldvik, Y. S. Reshetnikov, N. A. Kashulin, \& A. A. Lukin, 2003. Ontogenetic niche shifts and resource partitioning in a subarctic piscivore fish guild. Hydrobiologia 497: 109-119

Anwand, K., 1982. Produktionsbiologische Grundlagen und fischereiwirtschaftliche Maßnahmen zur weiteren Intensivierung der Aalwirtschaft in natürlichen Binnengewässern. Fortschritte der Fischereiwissenschaften 1: 117-121.

Arlinghaus, R., E.-M. Cyrus, E. Eschbach, M. Fujitani, D. Hühn, F. Johnston, T. Pagel, \& C. Riepe, 2015. Hand in Hand für eine nachhaltige Angelfischerei. Ergebnisse und Empfehlungen aus fünf Jahren praxisorientierter Forschung zu Fischbesatz und seinen Alternativen. Berichte des IGB 28: 200.

Beauchamp, D. A., E. R. Byron, \& W. A. Wurtsbaugh, 1994. Summer habitat use by littoral-zone fishes in lake tahoe and the effects of shoreline structures. North American Journal of Fisheries Management 14: 385-394

Benson, B. J., \& J. Magnuson, 1992. Spatial heterogeneity of littoral fish assemblages in lakes: relation to species diversity and habitat structure. Canadian Journal of Fisheries and Aquatic Sciences 49: 1493-1500

Blanchette, M. L., \& M. A. Lund, 2016. Pit lakes are a global legacy of mining: an integrated approach to achieving sustainable ecosystems and value for communities. Current Opinion in Environmental Sustainability 23: 28-34

Bohlin, T., S. Hamrin, T. G. Heggberget, G. Rasmussen, \& S. J. Saltveit, 1989. Electrofishing - theory and practice with special emphasis on salmonids. Hydrobiologia 173: 9-43

Brosse, S., \& S. Lek, 2002. Relationships between environmental characteristics and the density of age-0 Eurasian Perch Perca fluviatilis in the littoral zone of a lake: a nonlinear approach. Transactions of the American Fisheries Society 131: 1033-1043

Brosse, S., J.-F. Guegan, J.-N. Tourenq, \& S. Lek, 1999. The use of artificial neural networks to assess fish abundance and spatial occupancy in the littoral zone of a mesotrophic lake. Ecological Modelling 120: 299-311

Buston, P. M., \& J. Elith, 2011. Determinants of reproductive success in dominant pairs of clownfish: a boosted regression tree analysis. Journal of Animal Ecology 80: 528-538

Carey, M. P., K. O. Maloney, S. R. Chipps, \& D. H. Wahl, 2010. Effects of littoral habitat complexity and sunfish composition on fish production. Ecology of Freshwater Fish 19: 466-476

Casselman, J. M., 1996. Age, growth and environmental requirements of pike. In: Craig, J.F. (Ed), Pike: Biology and Exploitation. Chapman \& Hall, London, pp. 69-101.

Casselman, J. M., \& C. A. Lewis, 1996. Habitat requirements of northern pike (Esox lucius). Canadian Journal of Fisheries and Aquatic Sciences 53: 161-174

Chapman, C. A., \& W. C. Mackay, 1984. Direct observation of habitat utilization by Northern Pike. Copeia 1984: 255-258

Copp, G. H., 2010. Patterns of diel activity and species richness in young and small fishes of European streams: a review of 20 years of point abundance sampling by electrofishing. Fish and Fisheries 11: 439-460

Cunha, E. R., K. O. Winemiller, J. C. B. da Silva, T. M. Lopes, L. C. Gomes, S. M. Thomaz, \& A. A. Agostinho, 2019. $\alpha$ and $\beta$ diversity of fishes in relation to a gradient of habitat structural complexity supports the role of environmental filtering in community assembly. Aquatic Sciences Springer International Publishing 81: 1-12

de Leeuw, J. J., L. A. J. Nagelkerke, W. L. T. van Densen, K. Holmgren, P. A. Jansen, \& J. Vijverberg, 2003. Biomass size distributions as a tool for characterizing lake fish communities. Journal of Fish Biology 63: 1454-1475

Diehl, S., 1988. Foraging efficiency of three freshwater fishes: effects of structural complexity and light. Oikos 53: 207-214

Diekmann, M., U. W. E. Brämick, R. Lemcke, \& T. Mehner, 2005. Habitat-specific fishing revealed distinct indicator species in German lowland lake fish communities. Journal of Applied Ecology 42: 901-909

Downing, J. A., C. Plante, \& S. Lalonde, 1990. Fish production correlated with primary productivity, not the Morphoedaphic Index. Can. J. Fish. Aquat. Sci. 47: 1929-1936

Duarte, C. M., \& J. Kalf, 1986. Littoral slope as a predictor of the maximum biomass of submerged macrophyte communities. Limnology and Oceanography 31: 1072-1080

Dustin, D. L., \& B. Vondracek, 2017. Nearshore habitat and fish assemblages along a gradient of shoreline development. North American Journal of Fisheries Management Taylor \& Francis 37: 432-444

Eklöv, P., 1997. Effects of habitat complexity and prey abundance on the spatial and temporal distributions of perch (Perca fluviatilis) and pike (Esox lucius). Canadian Journal of Fisheries and Aquatic Sciences 54: 1520-1531

Eklöv, P., \& S. F. Hamrin, 1989. Predatory efficiency and prey selection: interactions between Pike Esox lucius, Perch Perca fluviatilis and Rudd Scardinus erythrophthalmus. Oikos 56: 149-156

Elith, J., J. R. Leathwick, \& T. Hastie, 2008. A working guide to boosted regression trees. Journal of Animal Ecology 77: 802-813

Elith, J., C. H. Graham, R. P. Anderson, M. Dudík, S. Ferrier, A. Guisan, R. J. Hijmans, F. Huettmann, J. R. Leathwick, A. Lehmann, J. Li, L. G. Lohmann, B. A. Loiselle, G. Manion, C. Moritz, M. Nakamura, Y. Nakazawa, J. McC. M. Overton, A. Townsend Peterson, S. J. Phillips, K. Richardson, R. Scachetti-Pereira, R. E. Schapire, J. Soberón, S. Williams, M. S. Wisz, \& N. E. Zimmermann, 2006. Novel methods improve prediction of species' distributions from occurrence data. Ecography 29: 129-151

Emmrich, M., S. Schälicke, D. Hühn, C. Lewin, \& R. Arlinghaus, 2014. No differences between littoral fish community structure of small natural and gravel pit lakes in the northern German lowlands. Limnologica Elsevier GmbH. 46: 84-93

Fischer, P., \& R. Eckmann, 1997. Seasonal changes in fish abundance, biomass and species richness in the littoral zone of a large European lake, Lake Constance, Germany. Archiv fur Hydrobiologie 139: 433-448

Gaeta, J. W., T. D. Ahrenstorff, J. S. Diana, W. W. Fetzer, T. S. Jones, Z. J. Lawson, M. C. McInerny, V. J. Santucci, \& M. J. Vander Zanden, 2018. Go big or ... don't? A fieldbased diet evaluation of freshwater piscivore and prey fish size relationships. Plos One 13: e0194092

Gallardo, J. M., J. C. E. García, E. G. Ceballos-Zúñiga, \& J. J. P. R. Pérez, 2006. Selective behaviour of a tench, Tinca tinca 
(L.), stock in different light-substrate combined conditions. Aquaculture International 14: 163-170

Gasith, A., 1991. Can littoral resources influence ecosystem processes in large, deep lakes. Internationale Vereinigung für Theoretische und Angewandte Limnologie: Verhandlungen 24: 1073-1076

Gee, A. S., 1978. The distribution and growth of coarse fish in gravel-pit lakes in south-east England. Freshwater Biology 8: 385-394

Glova, G. J., D. J. Jellyman, \& M. L. Bonnett, 2010. Factors associated with the distribution and habitat of eels (Anguilla spp.) in three New Zealand lowland streams. New Zealand Journal of Marine and Freshwater Research 32: 255-269

Gotceitas, V., \& P. Colgan, 1989. Predator foraging success and habitat complexity: quantitative test of the threshold hypothesis. Oecologia 80: 158-166

Greenwell, B., B. Boehmke, J. Cunningham, \& G. Developers, 2019. gbm: Generalized Boosted Regression Models. R package version 2.1.5., https://cran.r-project.org/package= gbm.

Grift, R. E., A. D. Buijse, W. L. T. van Densen, M. A. M. Machiels, J. Kranenbarg, J. G. P. Klein Breteler, \& J. J. G. M. Backx, 2003. Suitable habitats for 0-group fish in rehabilitated floodplains along the lower River Rhine. River Research and Applications 19: 353-374

Grimm, M. P., 1989. Northern pike (Esox lucius L.) and aquatic vegetation, tools in the management of fisheries and water quality in shallow waters. Hydrobiological Bulletin 23: 59-65

Grimm, M. P., \& M. Klinge, 1996. Pike and some aspects of its dependence on vegetation. In: Craig, J.F. (Ed.), Pike: Biology and Exploitation. Chapman \& Hall, London, pp. $125-156$.

Hampton, S. E., S. C. Fradkin, P. R. Leavitt, \& E. E. Rosenberger, 2011. Disproportionate importance of nearshore habitat for the food web of a deep oligotrophic lake. Marine and Freshwater Research 62: 350-358

Hanson, J. M., \& W. C. Leggett, 1982. Empirical prediction of fish biomass and yield. Canadian Journal of Fisheries and Aquatic Sciences 39: 257-263

Haugen, T. O., \& L. A. Vøllestad, 2018. In: Skov, C. and Nilsson, A. (Eds), Biology and Ecology of pike. CRC Press, Boca Raton, pp. 123-163. .

Helmus, M. R., \& G. G. Sass, 2008. The rapid effects of a wholelake reduction of coarse woody debris on fish and benthic macroinvertebrates. Freshwater Biology 53: 1423-1433

Hijmans, R. J., S. Phillips, J. Leathwick, \& J. Elith, 2017. dismo: species distribution modeling, https://cran.r-project.org/ package $=$ dismo.

Hofmann, N., \& P. Fischer, 2001. Seasonal changes in abundance and age structure of burbot Lota lota (L.) and stone loach Barbatula barbatula (L.) in the littoral zone of a large pre-alpine lake. Ecology of Freshwater Fish 10: 21-25

Höhne, L., M. Palmer, C. T. Monk, S. Matern, R. Nikolaus, A. Trudeau, \& R. Arlinghaus, 2020. Environmental determinants of perch (Perca fluviatilis) growth in gravel pit lakes and the relative performance of simple versus complex ecological predictors. Ecology of Freshwater Fish, https:// doi.org/10.1111/eff.12532.
Hölker, F., S. S. Haertel, S. Steiner, T. Mehner, \& I. Fisheries, 2002. Effects of piscivore-mediated habitat use on growth, diet and zooplankton consumption of roach: an individualbased modelling approach. Freshwater Biology 47: 2345-2358

Hutchinson, G. B., 1957. A Treatise on Limnology. Volume 1. Geography, Physics, and Chemistry. John Wiley \& Sons, Inc. New York.

ISO, 2004. Water quality - determination of phosphorus ammonium molybdat spectrometric method.

Jackson, D. A., 1993. Stopping rules in principal components analysis: a comparison of heuristical and statistical approaches. Ecology 74: 2204-2214

Jellyman, D. J., M. L. Bonnett, J. R. E. Sykes, \& P. Johnstone, 2002. Contrasting use of daytime habitat by two species of freshwater eel (Anguilla spp.) in New Zealand rivers. American Fisheries Society Symposium.

Jeppesen, E., J. P. Jensen, M. Søndergaard, T. Lauridsen, \& F. Landkildehus, 2000. Trophic structure, species richness and diversity in Danish lakes: changes along a phosphorus gradient. Freshwater Biology 45: 201-218

Jouffray, J. B., L. M. Wedding, A. V. Norström, M. K. Donovan, G. J. Williams, L. B. Crowder, A. L. Erickson, A. M. Friedlander, N. A. J. Graham, J. M. Gove, C. V. Kappel, J. N. Kittinger, J. Lecky, K. L. L. Oleson, K. A. Selkoe, C. White, I. D. Williams, \& M. Nyström, 2019. Parsing human and biophysical drivers of coral reef regimes. Proceedings of the Royal Society B: Biological Sciences 286: $1-10$

Kobler, A., T. Klefoth, C. Wolter, F. Fredrich, \& R. Arlinghaus, 2008. Contrasting pike (Esox lucius L.) movement and habitat choice between summer and winter in a small lake. Hydrobiologia 601: 17-27

Kobler, A., T. Klefoth, T. Mehner, \& R. Arlinghaus, 2009. Coexistence of behavioural types in an aquatic top predator: a response to resource limitation?. Oecologia 161: 837-847

Leathwick, J. R., J. Elith, M. P. Francis, \& P. Taylor, 2006. Variation in demersal fish species richness in the oceans surrounding New Zealand. Marine Ecology Progress Series 321: 267-281

Lewin, W.-C., N. Okun, \& T. Mehner, 2004. Determinants of the distribution of juvenile fish in the littoral area of a shallow lake. Freshwater Biology 49: 410-424

Lewin, W.-C., T. Mehner, D. Ritterbusch, \& U. Brämick, 2014. The influence of anthropogenic shoreline changes on the littoral abundance of fish species in German lowland lakes varying in depth as determined by boosted regression trees. Hydrobiologia 724: 293-306

Lorenzen, K., 2000. Allometry of natural mortality as a basis for assessing optimal release size in fish-stocking programmes. Canadian Journal of Fisheries and Aquatic Sciences 57: 2374-2381

Mantoura, R. F. C., \& C. A. Llewellyn, 1983. The rapid determination of algal chlorophyll and carotenoid pigments and their breakdown products in natural waters by reversephase high-performance liquid chromatography. Analytica Chimica Acta 151: 297-314

Matern, S., M. Emmrich, T. Klefoth, C. Wolter, R. Nikolaus, N. Wegener, \& R. Arlinghaus, 2019. Effect of recreationalfisheries management on fish biodiversity in gravel pit 
lakes, with contrasts to unmanaged lakes. Journal of Fish Biology 94: 865-881

Mehner, T., M. Diekmann, U. Brämick, \& R. Lemcke, 2005. Composition of fish communities in German lakes as related to lake morphology, trophic state, shore structure and human-use intensity. Freshwater Biology 50: 70-85

Monk, C. T., \& R. Arlinghaus, 2017. Encountering a bait is necessary but insufficient to explain individual variability in vulnerability to angling in two freshwater benthivorous fish in the wild. PLoS ONE 12: 1-25

Mueller, M., J. Pander, J. Knott, \& J. Geist, 2017. Comparison of nine different methods to assess fish communities in lentic flood-plain habitats. Journal of Fish Biology 91: 144-174

Murphy, J., \& J. P. Riley, 1962. A modified single solution method for the determination of phosphate in natural waters. Analytica Chimica Acta 27: 31-36

Nakayama, S., P. Doering-Arjes, S. Linzmaier, J. Briege, T. Klefoth, T. Pieterek, R. Arlinghaus, P. Doering-Arjes, S. Linzmaier, J. Briege, T. Klefoth, T. Pieterek, \& R. Arlinghaus, 2018. Fine-scale movement ecology of a freshwater top predator, Eurasian perch (Perca fluviatilis), in response to the abiotic environment over the course of a year. Ecology of Freshwater Fish 27: 1-15

Nikolaus, R., S. Matern, M. Schafft, T. Klefoth, A. Maday, C. Wolter, A. Manfrin, J. U. Lemm, \& R. Arlinghaus, 2020. Einfluss anglerischer Bewirtschaftung auf die Biodiversität von Baggerseen: Eine vergleichende Studie verschiedener gewässergebundener Organismengruppen. Lauterbornia 87: 153-181.

Nilsson, P. A., 2006. Avoid your neighbours: size-determined spatial distribution patterns among northern pike individuals. Oikos 113: 251-258

Nilsson, P. A., L. Jacobsen, S. Berg, \& C. Skov, 2009. Environmental conditions and intraspecific interference: unexpected effects of turbidity on pike (Esox lucius) foraging. Ethology 115: 33-38

Nilsson, J., O. Engstedt, \& P. Larsson, 2014. Wetlands for northern pike (Esox lucius L.) recruitment in the Baltic Sea. Hydrobiologia 721: 145-154

Oksanen, J., F. G. Blanchet, M. Friendly, R. Kindt, P. Legendre, D. McGlinn, P. R. Minchin, R. B. O'Hara, G. L. Simpson, P. Solymos, M. H. H. Stevens, E. Szoecs, \& H. Wagner, 2019. vegan: community ecology package. R package version 2.5-5, https://cran.r-project.org/package=vegan.

Okun, N., \& T. Mehner, 2005. Distribution and feeding of juvenile fish on invertebrates in littoral reed (Phragmites) stands. Ecology of Freshwater Fish 14: 139-14

Paradis, E., \& K. Schliep, 2018. ape 5.0: an environment for modern phylogenetics and evolutionary analyses in $\mathrm{R}$. Bioinformatics 35: 526-528

Paterson, A. W., \& A. K. Whitfield, 2000. Do shallow-water habitats function as refugia for juvenile fishes?. Estuarine, Coastal and Shelf Science 51: 359-364

Perrow, M. R., A. J. D. D. Jowitt, \& S. R. Johnson, 1996. Factors affecting the habitat selection of tench in a shallow eutrophic lake. Journal of Fish Biology 48: 859-870

Persson, L., \& P. Eklöv, 1995. Prey refuges affecting interactions between piscivorous perch and juvenile perch and roach. Ecology 76: 70-81

Persson, L., S. Diehl, L. Johansson, G. Andersson, \& S. F. Hamrin, 1991. Shifts in fish communities along the productivity gradient of temperate lakes-patterns and the importance of size-structured interactions. Journal of Fish Biology 38: 281-293

Pierce, R. B., \& C. M. Tomcko, 2005. Density and biomass of native Northern Pike populations in relation to basin-scale characteristics of North-Central Minnesota lakes. Transactions of the American Fisheries Society 134: 231-241

Poizat, G., \& D. Pont, 1996. Multi-scale approach to specieshabitat relationships: juvenile fish in a large river section. Freshwater Biology 36: 611-622

Pusey, B. J., \& A. H. Arthington, 2003. Importance of riparian zone to the conservation of freshwater fish: a review. Marine and Freshwater Research 54: 1-16

QGIS Development Team, 2019. QGIS Geographic Information System. Open Source Geospatial Foundation Project. http://qgis.osgeo.org.

R Core Team, 2019. R: A language and environment for statistical computing. R Foundation for Statistical Computing, Vienna, Austria. www.r-project.org.

Radomski, P., \& T. J. Goeman, 2001. Consequences of human lakeshore development on emergent and floating-leaf vegetation abundance. North American Journal of Fisheries Management 21: 46-61

Reid, S. M., 2011. Comparison of point and transect-based electrofishing to sample American eel (Anguilla rostrata) in wadeable riverine habitats. Aquatic Living Resources 24: 79-83

Říha, M., D. Ricard, M. Vašek, M. Prchalová, T. Mrkvička, T. Jůza, M. Čech, V. Draštík, M. Muška, M. Kratochvíl, J. Peterka, M. Tušer, J. Sed'a, P. Blabolil, M. Bláha, J. Kubečka, \& J. Wanzenbo, 2015. Patterns in diel habitat use of fish covering the littoral and pelagic zones in a reservoir. Hydrobiologia 747: 111-131

Rosell, R. S., \& K. C. MacOscar, 2002. Movements of pike, Esox lucius, in Lower Lough Erne, determined by markrecapture between 1994 and 2000. Fisheries Management and Ecology 9: 189-196

Sass, G. G., J. F. Kitchell, S. R. Carpenter, T. R. Hrabik, A. E. Marburg, \& M. G. Turner, 2006. Fish community and food web responses to a whole-lake removal of coarse woody habitat. Fisheries 31: 321-330

Sass, G. G., S. R. Carpenter, J. W. Gaeta, J. F. Kitchell, \& T. D. Ahrenstorff, 2012. Whole-lake addition of coarse woody habitat: response of fish populations. Aquatic Sciences 74: 255-266

Sass, G. G., J. D. Stafford, A. L. Rypel, \& J. D. Stafford, 2017. Inland fisheries habitat management: lessons learned from wildlife ecology and a proposal for change. Fisheries 42: 197-209.

Saulnier-Talbot, É., \& I. Lavoie, 2018. Uncharted waters: the rise of human-made aquatic environments in the age of the "Anthropocene." Anthropocene 23: 29-42

Savino, J. F., \& R. A. Stein, 1982. Predator-prey interaction between largemouth bass and bluegills as influenced by simulated, submersed vegetation. Transactions of the American Fisheries Society 111: 255-266

Savino, J. F., \& R. A. Stein, 1989. Behavioural interactions between fish predators and their prey: effects of plant density. Animal Behaviour 37: 311-321 
Scheuerell, M. D., \& D. E. Schindler, 2004. Changes in the spatial distribution of fishes in lakes along a residential development gradient. Ecosystems 7: 98-106

Schindler, D. E., \& M. D. Scheuerell, 2002. Habitat coupling in aquatic ecosystems. Oikos 98: 177-189

Šidák, Z., 1967. Rectangular confidence regions for the means of multivariate normal distributions. Journal of the American Statistical Association 62: 626-633

Simon, J., \& H. Dörner, 2014. Survival and growth of European eels stocked as glass- and farm-sourced eels in five lakes in the first years after stocking. Ecology of Freshwater Fish 23: $40-48$

Skov, C., \& A. Koed, 2004. Habitat use of $0+$ year pike in experimental ponds in relation to cannibalism, zooplankton, water transparency and habitat complexity. Journal of Fish Biology 64: 448-459

Skov, C., L. Jacobsen, \& S. Berg, 2003. Post-stocking survival of $0+$ year pike in ponds as a function of water transparency, habitat complexity, prey availability and size heterogeneity. Journal of Fish Biology 62: 311-322

Šmejkal, M., M. Prchalová, M. Čech, M. Vašek, M. Říha, T. Jůza, P. Blabolil, \& J. Kubečka, 2014. Associations of fish with various types of littoral habitats in reservoirs. Ecology of Freshwater Fish 23: 405-413.

Søndergaard, M., T. L. Lauridsen, L. S. Johansson, \& E. Jeppesen, 2018. Gravel pit lakes in Denmark: chemical and biological state. Science of the Total Environment Elsevier B.V. 612 : 9-17

Soni, A. K., B. Mishra, \& S. Singh, 2014. Pit lakes as an end use of mining: a review. Journal of Mining and Environment 5: 99-111

Stoll, S., P. Fischer, P. Klahold, N. Scheifhacken, H. Hofmann, \& K.-O. Rothhaupt, 2008. Effects of water depth and hydrodynamics on the growth and distribution of juvenile cyprinids in the littoral zone of a large pre-alpine lake. Journal of Fish Biology 72: 1001-1022

Strayer, D. L., \& S. E. G. Findlay, 2010. Ecology of freshwater shore zones. Aquatic Sciences 72: 127-163

Vander Zanden, M. J., Y. Vadeboncoeur, \& S. Chandra, 2011. Fish reliance on littoral-benthic resources and the distribution of primary production in lakes. Ecosystems 14: 894-903

Werner, E. E., \& J. D. Hall, 1988. Ontogenetic habitat shifts in bluegill: the foraging rate-predation risk trade-off. Ecology 69: 1352-1366

Werner, E. E., D. J. Hall, D. R. Laughlin, D. J. Wagner, L. A. Wilsmann, \& F. C. Funk, 1977. Habitat partitioning in a freshwater fish community. Journal of the Fisheries Research Board of Canada 34: 360-370.

Westrelin, S., R. Roy, L. Tissot-Rey, L. Bergès, \& C. Argillier, 2018. Habitat use and preference of adult perch (Perca fluviatilis L.) in a deep reservoir: variations with seasons, water levels and individuals. Hydrobiologia 809: 121-139

Whitfield, A. K., 1986. Fish community structure response to major habitat changes within the littoral zone of an estuarine coastal lake. Environmental Biology of Fishes 17: $41-51$

Winfield, I. J., 2004. Fish in the littoral zone: ecology, threats and management. Limnologica 34: 124-131.

Wright, S. W., S. W. Jeffrey, R. F. C. Mantoura, L. C. A, T. Bjornland, D. Repeta, \& N. Welschmeyer, 1991. Improved HPLC method for the analysis of chlorophylls and carotenoids from marine phytoplankton. Marine Ecology Progress Series 77: 183-196

Zalewski, M., \& I. G. Cowx, 1990. Factors affecting the efficiency of electric fishing In: Cowx, I.G. and Lamarque, P. (Ed), Fishing with Electricity. Fishing News Books, Blackwell Scientific Publications, Oxford, pp. 89-111. .

Zhao, T., G. Grenouillet, T. Pool, L. Tudesque, \& J. Cucherousset, 2016. Environmental determinants of fish community structure in gravel pit lakes. Ecology of Freshwater Fish 25: 412-421.

Ziegler, J. P., I. Gregory-Eaves, \& C. T. Solomon, 2017. Refuge increases food chain length: modeled impacts of littoral structure in lake food webs. Oikos 126: 1347-1356

Publisher's Note Springer Nature remains neutral with regard to jurisdictional claims in published maps and institutional affiliations. 